\title{
Protective effects of Myrica rubra flavonoids against hypoxia/reoxygenation-induced cardiomyocyte injury via the regulation of the PI3K/Akt/GSK3ß pathway
}

\author{
MIN WANG ${ }^{1 *}$, YING LIU ${ }^{2 *}$, RUI-LE PAN ${ }^{1}$, RUI-YING WANG ${ }^{1}$, SHI-LAN DING ${ }^{1}$, \\ WAN-RUI DONG ${ }^{3}$, GUI-BO SUN ${ }^{1}$, JING-XUE YE ${ }^{1}$ and XIAO-BO SUN ${ }^{1}$
}

\begin{abstract}
${ }^{1}$ Beijing Key Laboratory of Innovative Drug Discovery of Traditional Chinese Medicine (Natural Medicine) and Translational Medicine, Institute of Medicinal Plant Development, Chinese Academy of Medical Sciences and Peking Union Medical College, Beijing 100193; ${ }^{2}$ Heilongjiang University of Chinese Medicine, Harbin, Heilongjiang 150040; ${ }^{3}$ Harbin University of Commerce, Harbin, Heilongjiang 150076, P.R. China
\end{abstract}

Received September 6, 2018; Accepted March 6, 2019

DOI: $10.3892 / \mathrm{ijmm} .2019 .4131$

\begin{abstract}
Myrica rubra is well known for its delicious taste and highnutritional value. The presentstudyinvestigated the potential protective effects and mechanisms of $M$. rubra flavonoids (MRF) extract on isoproterenol (ISO)-induced myocardial injury in rats and hypoxia/reoxygenation (H/R) injury in H9c2 cardiomyocytes. An in vivo study revealed that MRF decreased serum cardiac enzyme levels, ameliorated pathological heart alterations and increased the antioxidant potential. The in vitro investigation demonstrated that MRF inhibited cell death, reactive oxygen species (ROS) accumulation, mitochondrial membrane depolarization, apoptosis rate and caspase-3 activation and enhanced the $\mathrm{Bcl}-2 / \mathrm{Bax}$ ratio during $\mathrm{H} / \mathrm{R}$ injury. These effects were accompanied by the phosphorylation of protein kinase B (Akt) and glycogen synthase kinase (GSK)-3 $\beta$. Further mechanism studies demonstrated that LY294002, a specific inhibitor of phosphoinositide 3-kinase (PI3K), abolished the MRF-mediated cardioprotection against H/R-induced apoptosis and ROS overproduction. Collectively, these results suggested that MRF exerts cardioprotective effects by attenuating oxidative damage and cardiomyocyte apoptosis most likely via a PI3K/Akt/GSK3 $\beta$-dependent mechanism.
\end{abstract}

Correspondence to: Professor Gui-Bo Sun or Professor Xiao-Bo Sun, Beijing Key Laboratory of Innovative Drug Discovery of Traditional Chinese Medicine (Natural Medicine) and Translational Medicine, Institute of Medicinal Plant Development, Chinese Academy of Medical Sciences and Peking Union Medical College, 151 Malianwa North Road, Haidian, Beijing 100193, P.R. China

E-mail: gbsun@implad.ac.cn

E-mail:xbsun@implad.ac.cn

${ }^{*}$ Contributed equally

Key words: Myrica rubra flavonoids, heart, ischemia/reperfusion, reactive oxygen species, phosphoinositide 3-kinase/protein kinase

\section{Introduction}

Coronary heart disease is one of the leading causes of mortality globally (1). Myocardial ischemia/reperfusion (I/R) injury is a common cardiovascular problem that leads to augmented cardiovascular dysfunction and further cell death following myocardial ischemia or cardiac operation in patients with coronary heart disease (2). The mechanisms of I/R injury are complicated and multifactorial, including excessive reactive oxygen species (ROS) production, intracellular calcium imbalance, mitochondrial dysfunction, exaggerated inflammation and/or programmed cell death $(3,4)$. Notably, excessive intracellular ROS production associated with apoptotic cell death has a direct effect on the cellular structure and function in myocardial tissue injury during myocardial ischemia and in particular, the myocardial reperfusion phase (5). Therefore, preventing oxidative stress and cardiomyocyte apoptosis may be an effective treatment for coronary heart disease.

Myrica rubra (Lour.) S. et Zucc., which is of high nutritional and medicinal value, is an important subtropical fruit tree that is widely distributed in China and other Asian countries $(6,7)$. The fruit is very appealing due to its pleasant sweet/sour flavor and is also popularly applied in wine- and juice-making (8). Additionally, the bark of M. rubra (Myricae cortex) is traditionally used as a natural drug for treating bruises, swelling and stomach and duodenal ulcers in Japan and China. Pharmacological studies have demonstrated that $M$. rubra extract exhibits various biological functions, including antioxidant, anti-inflammatory, antibacterial and anticancer activities $(9,10)$. Numerous phytochemicals, including flavonoids, tannins and triterpenes, can be isolated from $M$. rubra $(11,12)$. Notably, flavonoids, including myricetin and quercetin, which are major constituents of M. rubra, have drawn considerable attention because of their health-promoting functions $(13,14)$. Previous studies have revealed that M.rubra flavonoids exhibit strong cellular antioxidant activity (15) and possess excellent lipid-lowering activities (14). These results suggest that $M$. rubra flavonoids hold immense possibility to be developed as a novel natural agent for preventing and 
treating cardiovascular disease. However, the cardioprotective effects of M. rubra flavonoids (MRF) against I/R injury to cardiac myocytes remain unknown.

Therefore, in the present study, the protective effects of MRF against isoproterenol (ISO)-mediated myocardial injury were first examined in vivo and hypoxia/reoxygenation (H/R)-induced cardiomyocyte injuries in vitro. Furthermore, the role of the phosphoinositide 3-kinase (PI3K)-protein kinase B (Akt) signaling pathway in the cardioprotection of MRF was investigated.

\section{Materials and methods}

Preparation of MRF. The bark of M. rubra was purchased from the local market in Ningbo (Zhejiang, China). MRF was provided and chemically identified at the Institute of Medicinal Plant Development (Beijing, China) (16). Briefly, the sliced bark of M. rubra (500 g) was extracted with methanol using reflux extraction three times (each time for $1 \mathrm{~h}$ ). The extracts were combined and evaporated in vacuo. The concentrate was diluted with distilled water, subjected to a column containing D101 macroporous resin $(1 \mathrm{~kg}$; Cangzhou Bon Cang Bon Adsorber Technology Co., Ltd., Cangzhou, China) and eluted successively with ethanol-water $(1: 9, \mathrm{v} / \mathrm{v}$ and ethanol-water $(7: 3, v / v)$. The ethanol was evaporated in vacuo to yield a pale yellow residue $(35 \mathrm{~g})$ for further uses.

Ultra-performance liquid chromatography (UPLC) analysis of $M R F$. The contents of three markers in MRF were analyzed using UPLC analysis (16), which was performed on a Waters ACQUITY UPLC (ELSD) system. An ACQUITY UPLC BEH $\mathrm{C} 18(50 \mathrm{x} 2.1 \mathrm{~mm} \mathrm{ID}, 1.7 \mu \mathrm{m})$ was used with an injection volume of $2 \mu \mathrm{l}$ for UPLC separation. The mobile phases consisted of (A) acetonitrile and (B) $\mathrm{H}_{2} \mathrm{O}$ at a flow rate of $0.4 \mathrm{ml} / \mathrm{min}$. The gradient elution was used as follows: $0 \rightarrow 30 \mathrm{~min}, 5-95 \% \mathrm{~A}$; $30 \rightarrow 35 \mathrm{~min}, 95 \%$ A. Column temperature was set as $40^{\circ} \mathrm{C}$. $\mathrm{UV}$ absorption was measured at $354 \mathrm{~nm}$. All solutions were filtered through a $0.22 \mu \mathrm{m}$ filter prior to detection. Peak identification in the samples was performed with the retention time compared with the standard. The content of each compound was quantified using the external standard method using the area under the peak. As presented in Fig. 1 and Table I, the contents of myricitrin, quercetin-3-O-rhamnoside and quercetin were $85.52,0.86$ and $0.69 \%$, respectively.

Animals. A total of 908 week-old male Sprague-Dawley rats weighing 200-220 g were purchased from the Beijing Vital River Laboratory Animal Technology Co., Ltd. (Beijing, China). The animals were housed under standard laboratory conditions $\left(25 \pm 1^{\circ} \mathrm{C}, 60 \%\right.$ humidity and $12 \mathrm{~h}$ photoperiod), provided with standard rodent chow and allowed free access to water. All procedures were approved by the Laboratory Animal Ethics Committee of the Institute of Medicinal Plant Development, Peking Union Medical College (Beijing, China) and complied with the Guide for the Care and Use of Laboratory Animals published by the US National Institute of Health (NIH Publication, 8th edition, 2011).

Experimental protocols. A total of 90 Sprague-Dawley rats were randomly assigned to six groups: 1, Control; 2, ISO treatment; 3, ISO with $51 \mathrm{mg} / \mathrm{kg}$ MRF; 4, ISO with $10 \mathrm{mg} / \mathrm{kg}$ MRF; 5, ISO with $20 \mathrm{mg} / \mathrm{kg}$ MRF; and 6, Di-ao-xin-xue-kang capsule (Di-ao, $80 \mathrm{mg} / \mathrm{kg}$ ) as positive control. Groups 1 and 2 were intragastrically provided with the vehicle (1\% Tween 80$)$. Groups 3, 4 and 5 were intragastrically dosed with MRF (5, 10 and $20 \mathrm{mg} / \mathrm{kg}$ ) for 15 days. Group 6 was intragastrically administered with Di-ao ( $80 \mathrm{mg} / \mathrm{kg})$ for 15 days. Following $1 \mathrm{~h}$ of MRF and Di-ao administration on days 14 and 15, rats in groups 2 to 6 were injected with ISO ( $4 \mathrm{mg} / \mathrm{kg}$, injectio hypodermaticus), whereas rats in group 1 received saline solution.

Preparation of samples and measurement of biochemical variables. Following intraperitoneally anesthetizing the rats (320-350 g) with urethane solution $(1 \mathrm{~g} / \mathrm{kg})$, blood samples $(5 \mathrm{ml})$ were collected for serum creatine kinase (CK), aspartate aminotransferase (AST) and lactate dehydrogenase (LDH) measurement using the appropriate kits (Nanjing Jiancheng Bioengineering Institute, Nanjing, China). Following the preparation of blood samples, the hearts were excised and myocardial homogenates were prepared for analyzing malondialdehyde (MDA), superoxide dismutase (SOD) and catalase (CAT) activities using the corresponding kits (Nanjing Jiancheng Bioengineering Institute). Experiments were performed according to the manufacturer's protocol.

Histopathological examination. The heart apex was fixed in $10 \%$ formalin for $24 \mathrm{~h}$ at room temperature, routinely processed and embedded in paraffin. The paraffin sections ( $3 \mathrm{~mm}$ ) were cut on glass slides, stained with hematoxylin for $5 \mathrm{~min}$ and eosin for $1 \mathrm{~min}(\mathrm{H} \& \mathrm{E})$ at room temperature and examined under a light microscope (CKX41; Olympus Corporation, Tokyo, Japan). Examination was performed by a pathologist blinded to the experimental groups.

Cell culture and treatment. Rat embryonic cardiomyoblast-derived H9c2 cardiomyocytes (Cell Bank of the Chinese Academy of Sciences, Shanghai, China) were cultured as previously described (17). Briefly, H9c2 cells were cultured in high-glucose Dulbecco's modified Eagles medium (DMEM) supplemented with $10 \%$ (v/v) fetal bovine serum (both Gibco; Thermo Fisher Scientific, Inc., Waltham, MA, USA), $1 \%$ penicillin/streptomycin (v/v) and $2 \mathrm{mM} \mathrm{L-glutamine}$ at $37^{\circ} \mathrm{C}$ with $5 \% \mathrm{CO}_{2}$ incubation. For all the experiments, the cells were plated at an appropriate density in accordance with the experimental design and were grown for $24 \mathrm{~h}$ to reach $70-80 \%$ confluence before experimentation.

The H/R model was built according to previously published methods $(17,18)$. H9c2 cardiomyocytes were cultured under hypoxia for $6 \mathrm{~h}$ and then removed from the anaerobic glove box (TYPE C; Coy Laboratory Products, Inc., Grasslake, MI, USA) to a regular incubator with the medium replaced by normal medium to mimic reperfusion. In the MRF-treated group, the H9c2 cardiomyocytes subjected to $\mathrm{H} / \mathrm{R}$ were treated with $\mathrm{MRF}(6.25 \mu \mathrm{g} / \mathrm{ml})$ for $12 \mathrm{~h}$. In the inhibitor-treated group, the cells were pre-incubated with $20 \mu \mathrm{M}$ LY294002 for $1 \mathrm{~h}$ prior to treatment with MRF. The concentration of LY294002, was determined based on data present in the literature and the authors' preliminary experiments (19). 
Table I. Ultra-pressure liquid chromatography quantification of Myrica rubra flavonoids.

\begin{tabular}{|c|c|c|c|c|c|}
\hline Peak & Chemical name & $\mathrm{tR}(\min )$ & Area $(m v * s)$ & Height (mv) & $\%$ Area \\
\hline 1 & Myricitrin & 5.545 & 9152352 & 2742517 & 85.52 \\
\hline 2 & Quercetin-3-O-rhamnoside & 6.552 & 92418 & 40823 & 0.86 \\
\hline 3 & Quercetin & 6.982 & 74023 & 18571 & 0.69 \\
\hline 4 & Myricanol & 12.656 & 378747 & 130856 & 3.54 \\
\hline 5 & Myricanone & 18.779 & 1004491 & 273583 & 9.39 \\
\hline
\end{tabular}

$\mathrm{T}_{\mathrm{R}}$, retention time.

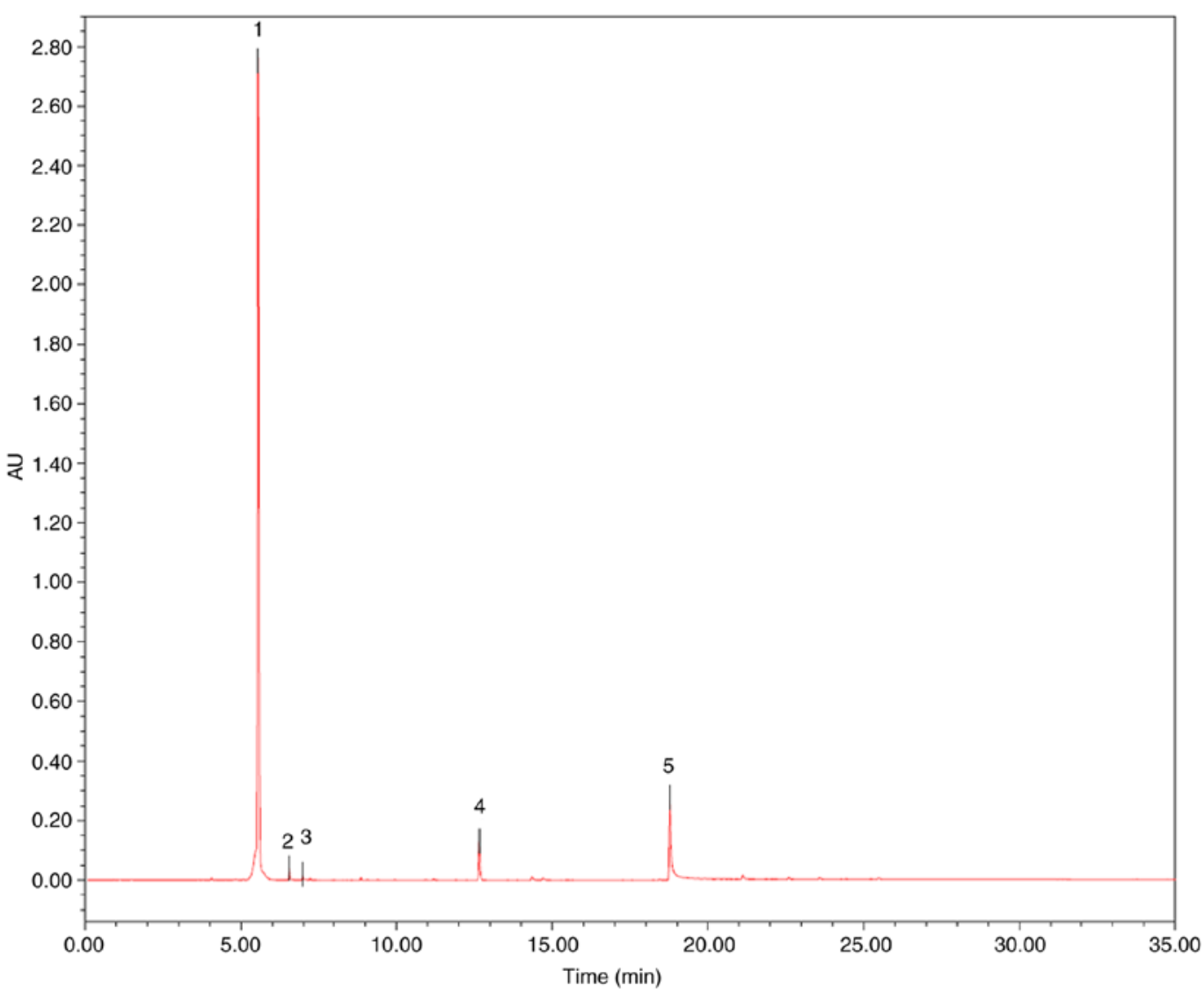

Figure 1. The ultra-performance liquid chromatography fingerprint analysis of the Myrica rubra flavonoids and its main components. The name of the compounds: (1) Myricitrin; (2) Quercetin-3-O-rhamnoside; (3) Quercetin; (4) Myricanol; (5) Myricanone. AU, arbitrary units.

Cell viability analysis. Cell viability was determined using an MTT assay as previously described (20). H9c2 cells were seeded at a density of $1 \times 10^{4}$ cells/well in 96 -well plates. Following the different treatments, the cells were incubated with $20 \mu \mathrm{l}$ of MTT $(5 \mathrm{mg} / \mathrm{ml})$ each well for $4 \mathrm{~h}$. The supernatant was subsequently removed and the formazan crystals were dissolved in dimethyl sulfoxide. The absorbance was detected at $570 \mathrm{~nm}$ using a microplate reader (Infinite M1000; Tecan Group, Ltd., Mannedorf, Switzerland).

Measurement of $\mathrm{LDH}$ and MDA levels and SOD, CAT and glutathione-peroxidase (GSH-PX) activities. H9c2 cells were cultured in six-well plates at $5 \times 10^{5}$ cells/well. The cultured cells were incubated with different MRF concentrations following exposure to hypoxia. The supernatant and cells were then collected following different treatments to determine the LDH and MDA levels and SOD, CAT and GSH-PX activities using the corresponding detection kits (Nanjing Jiancheng Bioengineering Institute, Nanjing, China) in accordance with the manufacturers' protocol (21). For the LDH release assay, the cell medium was removed for the analysis of extracellular LDH activity, which could catalyze the conversion of lactate to pyruvate and then reacted with 2,4-dinitrophenylhydrazine to give the brownish red color in basic solution. After each reaction, the sample was analyzed and the absorbance was read at wavelength $440 \mathrm{~nm}$. The results were expressed as U/L. For the lipid peroxidation assay, MDA was measured as an indicator of lipid peroxidation according to the thiobarbituric acid (TBA) method. The method was based on the spectrophotometric measurement of the red color produced during the reaction to 
TBA with MDA. The optical density was measured at $532 \mathrm{~nm}$. For the SOD activity assay, the SOD activity was detected with an assay kit according to xanthine oxidase method. The assay used the xanthine-xanthine oxidase system to produce superoxide anions, which react with 2-(4-iodophenyl)-3-(4-nitrophenol-5-phenyltetrazolium chloride) to form a red formazan dye and the absorbance at $550 \mathrm{~nm}$ was determined. For the CAT activity assay, the hydrogen peroxide $\left(\mathrm{H}_{2} \mathrm{O}_{2}\right)$ was catalyzed by CAT for $1 \mathrm{~min}$ at $37^{\circ} \mathrm{C}$ and then terminated by forming stable complexes with ammonium molybdate. The CAT level was calculated by recording the visible absorbance of these complexes at $405 \mathrm{~nm}$. For the GSH-Px activity assay $1 \mathrm{mmol}$ $\mathrm{L}^{-1} \mathrm{GSH}$ was incubated with cells for $5 \mathrm{~min}$ at $37^{\circ} \mathrm{C}$ and then centrifuged for $10 \mathrm{~min}$ at $1,800 \mathrm{x} \mathrm{g}$ at room temperature. The GSH in the supernatant reduced 5,5'-dithiobis 2-nitrobenzoic acid to 2-nitro-5-thiobenzoate anion (NTP). The GSH-Px level was calculated by recording the absorbance of NTP at $412 \mathrm{~nm}$. Non-enzymatic control was used to eliminate the interference from endogenous GSH.

Detection of intracellular ROS production. Intracellular ROS production was monitored using a total ROS detection kit in accordance with the manufacturer's protocol (Enzo Life Sciences, Inc., Farmingdale, NY, USA). After different treatments, the cells were harvested and washed with $1 \mathrm{X}$ wash buffer. Subsequently, the supernatant was discarded and the cells were incubated with $500 \mu \mathrm{l}$ of ROS detection solution and stained in the dark at $37^{\circ} \mathrm{C}$ for $30 \mathrm{~min}$. The fluorescence was analyzed using a flow cytometer with CellQuest software, version 5.0 (FACS Calibur ${ }^{\mathrm{TM}}$, BD Biosciences; Becton, Dickinson and Company, Franklin Lakes, NJ, USA) (22).

Flow cytometric detection of cell apoptosis rate. The percentages of early apoptosis and necrosis were detected using an Annexin V FITC/PI apoptosis kit (Invitrogen; Thermo Fisher Scientific, Inc.). Following drug treatment, the cells were harvested, washed twice with cold PBS and incubated in the dark with $5 \mu \mathrm{l}$ of FITC-Annexin V and $1 \mu \mathrm{l}$ of PI working solution $(100 \mu \mathrm{g} / \mathrm{ml})$ for $15 \mathrm{~min}$ at room temperature. Apoptosis rate was measured through flow cytometry analysis.

Determination of mitochondrial transmembrane potential $\left(\Delta \Psi_{m}\right)$. JC-1 (Invitrogen; Thermo Fisher Scientific, Inc.) was used to determine the effect of MRF on MMP. After treatments, $\mathrm{H} 9 \mathrm{c} 2$ cells $\left(5 \times 10^{5}\right.$ cells/well) were harvested and incubated with $2 \mu \mathrm{M} \mathrm{JC}-1$ at $37^{\circ} \mathrm{C}$ for $30 \mathrm{~min}$ in the dark and washed twice with PBS. Cells labeled with JC-1 were analyzed by BD FACSCalibur flow cytometry using $488 \mathrm{~nm}$ excitation and green $(525 \mathrm{~nm})$ or orange-red $(575 \mathrm{~nm})$ emission wavelengths with CellQuest software, version 5.0 (BD Biosciences; Becton, Dickinson and Company). The change in mitochondrial membrane potential was expressed as the ratio of red to green fluorescence intensity.

Analysis of caspase-3 activation. Caspase-3 activity was measured using a fluorescein active caspase-3 staining kit (BioVision, Inc., Milpitas, CA, USA). Briefly, $300 \mu 1$ $\left(1 \times 10^{6}\right.$ cells $\left./ \mathrm{ml}\right)$ of culture was incubated with $1 \mu \mathrm{l}$ of the substrate FITC-DEVD-FMK for $1 \mathrm{~h}$ at $37^{\circ} \mathrm{C}$. Then the supernatant was removed and the cells were resuspended in $300 \mu \mathrm{l}$ buffer following being washed twice with wash buffer and subjected to a microplate reader (Infinite M1000; Tecan Group, Ltd.) at $400 \mathrm{~nm}$ excitation and $505 \mathrm{~nm}$ emission wavelength.

Western blot analysis. Total cell lysate preparation and western blot analysis were performed as previously described (20). Briefly, H9c2 cardiomyocytes were lysed in Mammalian Protein Extraction Reagent (CWBioTech, Beijing, China) containing $1 \%$ phenylmethylsulfonyl fluoride. Equal amounts of protein $(20 \mu \mathrm{g})$ from each sample were separated by $10 \%$ SDS-PAGE and then transferred onto a nitrocellulose membrane. After being blocked ( $2 \mathrm{~h}$, room temperature) with $5 \%(\mathrm{w} / \mathrm{v})$ non-fat milk powder, the membranes were incubated overnight at $4^{\circ} \mathrm{C}$ with appropriate primary antibodies. The primary antibodies (Abcam, Cambridge, UK) used were as follows: Rabbit monoclonal anti-Akt1 (phospho S473) antibody (cat. no. ab81283; $1: 2,000)$, rabbit monoclonal anti-Akt1/2/3 antibody (cat. no. ab185633; 1:2,000), rabbit polyclonal anti-GSK3 $\beta$ (phospho S9) antibody (cat. no. ab131097; 1:1,000), rabbit polyclonal anti-GSK3 $\beta$ antibody (cat. no. ab131356; 1:1,000), rabbit polyclonal anti-Bcl-2 antibody (cat. no. ab196495; 1:1,000), rabbit polyclonal anti-Bax antibody (cat. no. ab199677; 1:1,000) and rabbit polyclonal anti- $\beta$ actin antibody (cat. no. ab8227; 1:1,000). After washing, the membranes were incubated for $1 \mathrm{~h}$ with the respective horseradish peroxidase-conjugated secondary antibodies at room temperature. Finally, the membranes were developed by enhanced chemiluminescence using a ChemiDoc ${ }^{\mathrm{TM}}$ XRS+ system (Bio-Rad Laboratories, Inc., Hercules, CA, USA). Densitometric analysis of the bands was performed using Gel Pro Analyzer version 6.0 (Media Cybernetics, Inc., Rockville, MD, United States).

Statistical analysis. Results are expressed as the mean \pm standard deviation of three independent experiments. Comparisons between different groups were performed using a Student's t-test or one-way analysis of variance followed by post hoc analysis with Tukey's multiple comparison test using Prism 5.00 software (GraphPad Software, Inc., La Jolla, CA, USA). P<0.05 was considered to indicate a statistically significant difference.

\section{Results}

$M R F$ prevents ISO-induced cardiac injury in rats. The levels of serum cardiac enzymes (CK, AST and LDH) and the activities of anti-oxidant enzymes (MDA, SOD, and CAT) were determined in the different animal groups to analyze the role of MRF on ISO-induced myocardial injury in rats. Fig. 2A and B demonstrated that MRF treatment significantly decreased the levels of $\mathrm{LDH}, \mathrm{CK}$, AST and MDA $(\mathrm{P}<0.05)$, as well as enhanced the activities of SOD and CAT, relative to those of the ISO group $(\mathrm{P}<0.05)$. Morphological alterations in the myocardial cells were determined through $\mathrm{H} \& \mathrm{E}$ staining under a light microscope. No abnormal changes were detected in the control and positive control groups, whereas considerable myocardial necrosis, fibrosis and neutrophil granulocyte infiltration of the heart were observed in the ISO group. MRF pretreatment groups markedly reduced the pathological alterations by ISO (Fig. 2C).

MRF ameliorates the $H / R$-induced cytotoxicity in $H 9 c 2$ cardiomyocytes. The protective effect of MRF against 
A

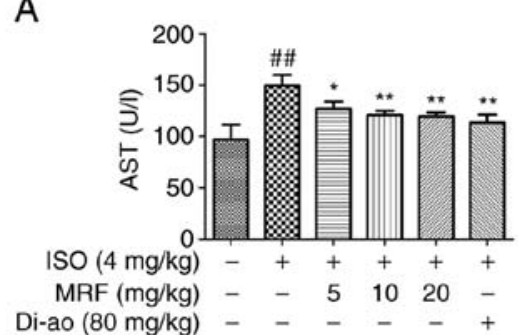

B

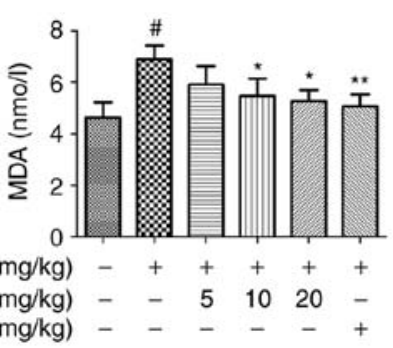

C

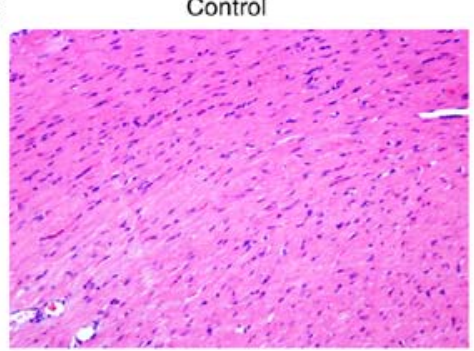

ISO+MRF $(10 \mathrm{mg} / \mathrm{kg})$

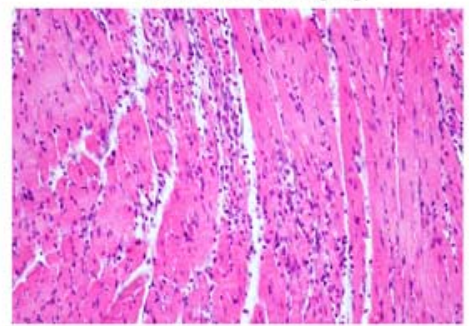

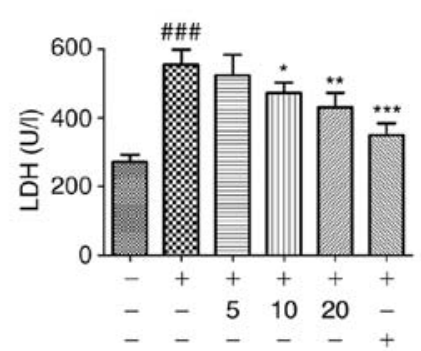

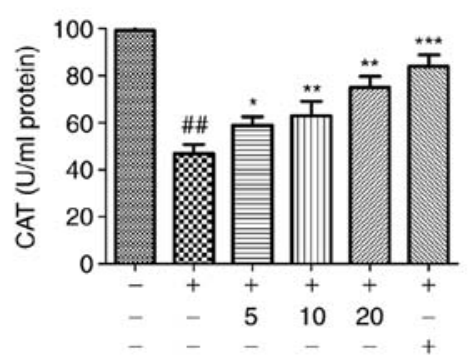

ISO

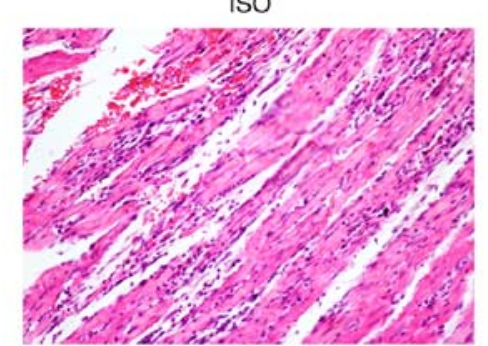

ISO+MRF $(20 \mathrm{mg} / \mathrm{kg})$

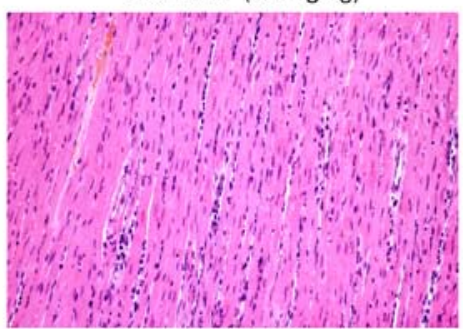

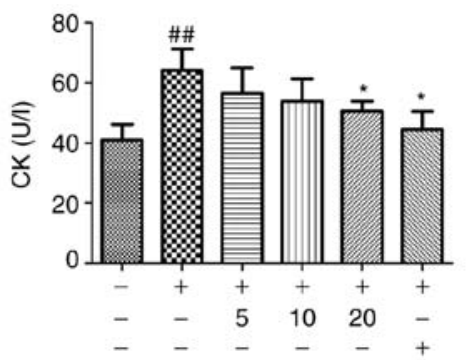
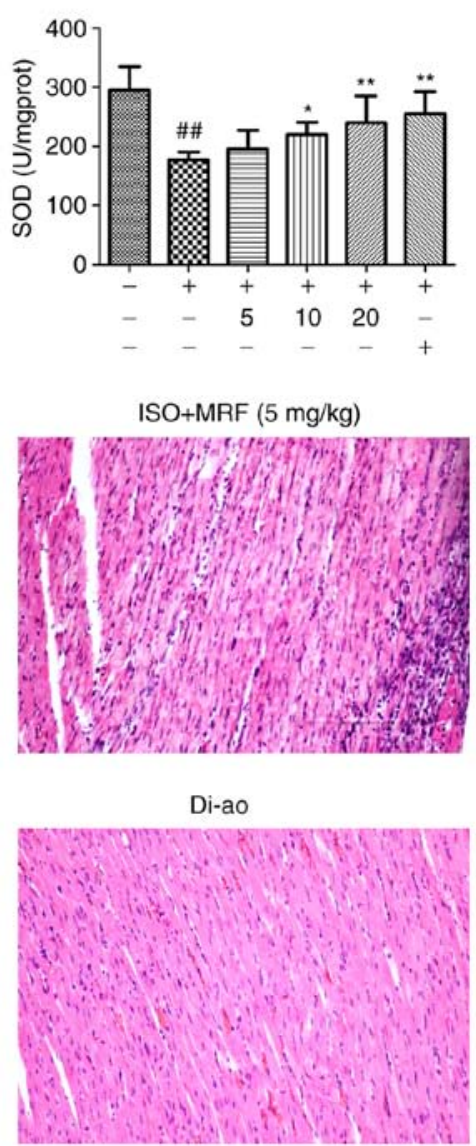

Figure 2. Effects of MRF on ISO-induced myocardial injury in vivo. (A) The effects of MRF on the levels of serum cardiac enzymes (CK, AST and LDH). (B) The effects of MRF on the activities of MDA, SOD and CAT in myocardial homogenates in rats. (C) The effects of MRF on the pathological alterations in rat hearts as indicated by hematoxylin and eosin staining (magnification, $\mathrm{x} 200$ ). Data ( $\mathrm{n}=10$ per group) are expressed as the mean \pm standard deviation. ${ }^{\#} \mathrm{P}<0.05$, ${ }^{\# \#} \mathrm{P}<0.01$ and ${ }^{\# \# \#} \mathrm{P}<0.001$ vs. the control group; ${ }^{*} \mathrm{P}<0.05,{ }^{* *} \mathrm{P}<0.01$ and ${ }^{* * *} \mathrm{P}<0.001$ vs. the ISO group. MRF, Myrica rubra flavonoids; Di-ao, Di-ao-xin-xue-kang capsule; ISO, isoproterenol; CK, creatine kinase; AST, aspartate aminotransferase; LDH: Lactate dehydrogenase; MDA, malondialdehyde SOD, superoxide dismutase; CAT, catalase.

H/R-induced cell death was detected using an MTT assay. The cells were exposed to hypoxia for $6 \mathrm{~h}$ to mimic injury and then subjected to different MRF concentrations (1.5625, 3.125 and $6.25 \mu \mathrm{g} / \mathrm{ml}$ ) for different periods (4, 12 and $24 \mathrm{~h}$ ). Fig. 3 demonstrates that MRF treatment significantly alleviated the $\mathrm{H} / \mathrm{R}$-induced reduction in cell viability and $6.25 \mu \mathrm{g} / \mathrm{ml}$ MRF for $12 \mathrm{~h}$ exhibited the most significant protective effect $(\mathrm{P}<0.05)$. Therefore, $6.25 \mu \mathrm{g} / \mathrm{ml} \mathrm{MRF}$ for $12 \mathrm{~h}$ was chosen for further experiments. As an indicator of cell injury, LDH levels were measured. As presented in Fig. 3B, MRF treatment significantly dose-dependently decreased the LDH levels in the culture medium $(\mathrm{P}<0.05)$.

MRF reduces oxidative stress by $H / R$ in $H 9 c 2$ cardiomyocytes. The membrane lipid oxidation level in oxidative damage was detected by MDA formation (23). In Fig. 4, the H/R group exhibited a significant increase in intracellular MDA levels $(\mathrm{P}<0.01)$, whereas the MRF treatment groups prevented MDA formation compared with the $\mathrm{H} / \mathrm{R}$ group. In addition, $\mathrm{MRF}$ treatment effectively enhanced the activities of the endogenous antioxidative enzymes SOD, CAT and GSH-Px relative to that of the H/R group.

ROS generation is a common response to cell injury (3). ROS production was monitored by flow cytometry (Fig. 5A). As presented in Fig. 5B, the H/R group significantly increased the intracellular ROS levels compared with the control $(\mathrm{P}<0.01)$. However, MRF post-conditioning significantly attenuated the intracellular ROS levels induced by $H / R$ in H9c2 cells $(\mathrm{P}<0.01)$. These results revealed that MRF protects $\mathrm{H} / \mathrm{R}$-induced cell injury by inhibiting ROS production. 
A

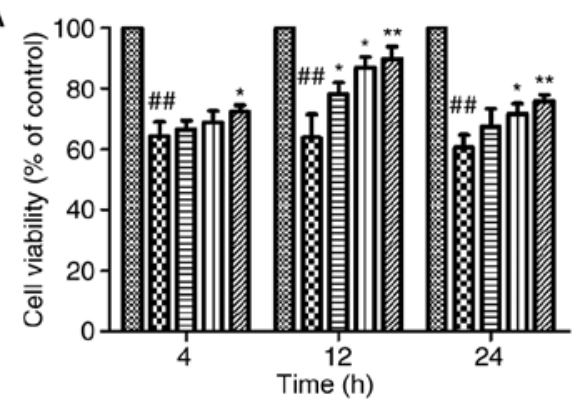

B

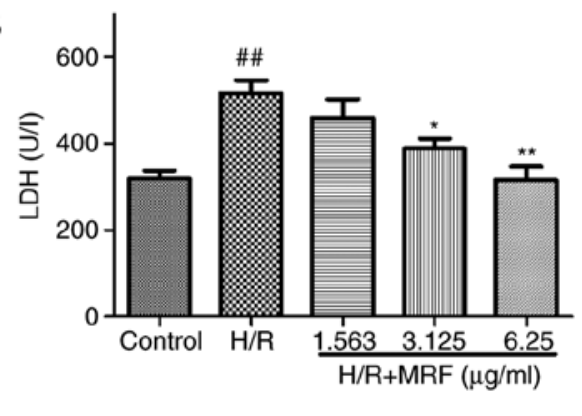

Figure 3. Effects of MRF on H/R-induced cell injury in H9c2 cells. (A) The cells were incubated with different concentrations $(1.563,3.125 \mathrm{and} 6.25 \mu \mathrm{g} / \mathrm{ml})$ of MRF for different times $(4,12$, and $24 \mathrm{~h}$ ) following hypoxia for $6 \mathrm{~h}$. Cell viability was detected by MTT assay. (B) The effect of MRF on the level of extracellular LDH leakage. The data are presented as the mean \pm standard deviation from three independent experiments. ${ }^{\# \prime} \mathrm{P}<0.01 \mathrm{vs}$. control; ${ }^{*} \mathrm{P}<0.05 \mathrm{vs}$. H/R-treated cells; *** $\mathrm{P}<0.01$ vs. H/R-treated cells. MRF, Myrica rubra flavonoids; H/R, hypoxia/reoxygenation; LDH, lactate dehydrogenase.
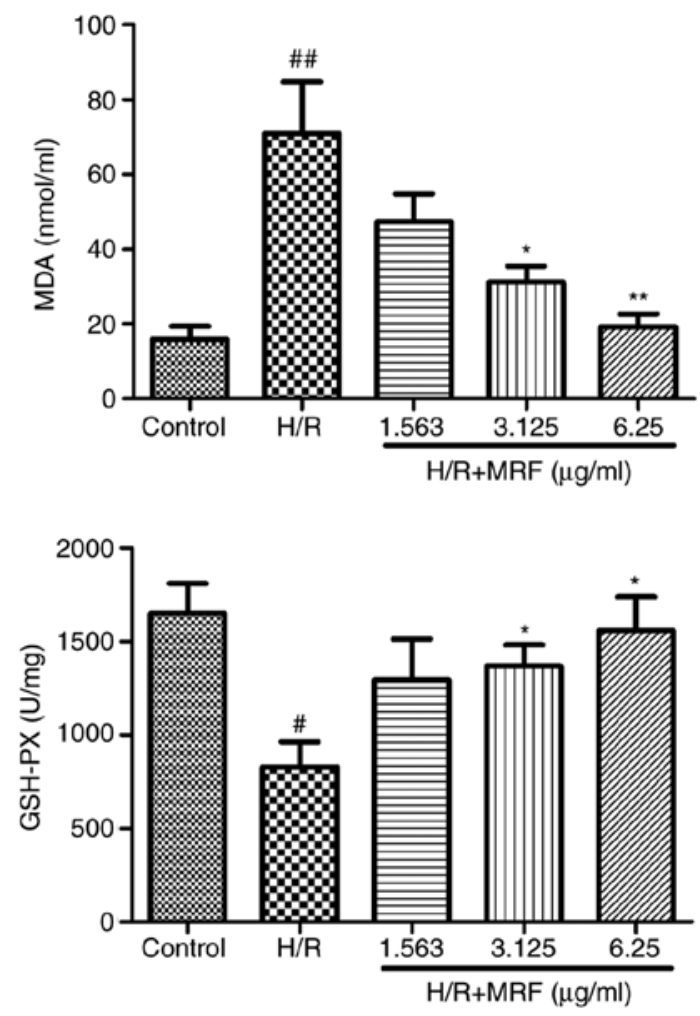
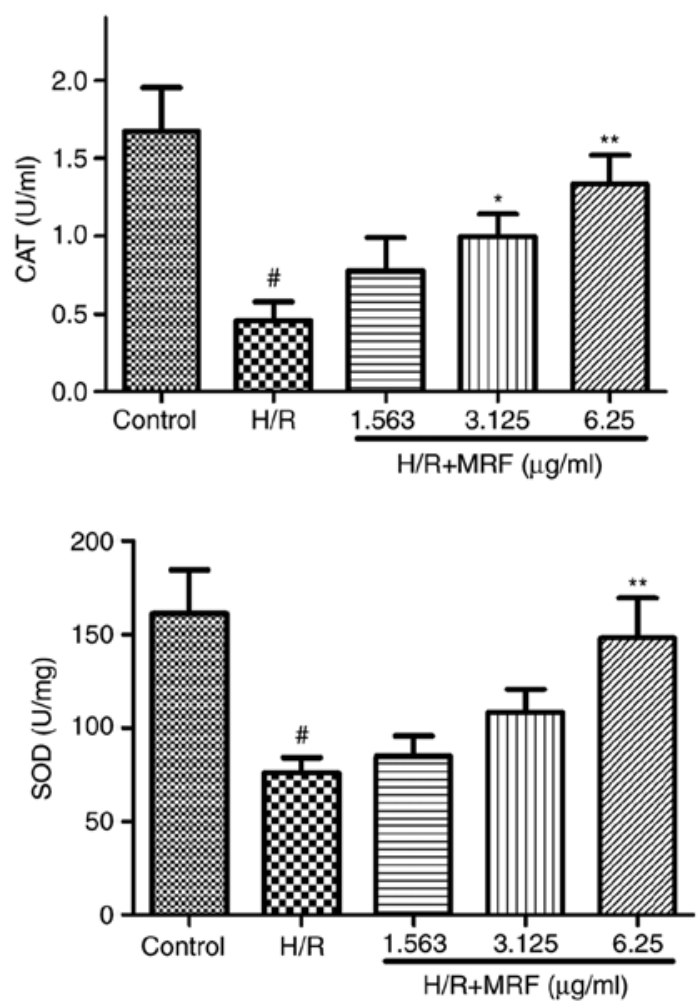

Figure 4. Effects of MRF on lipid oxidation and antioxidative activities in H/R-induced H9c2 cell injury. Cells incubated with different concentrations $(1.5625,3.125$ and $6.25 \mu \mathrm{g} / \mathrm{ml})$ of MRF for $12 \mathrm{~h}$ following hypoxia for $6 \mathrm{~h}$. The data are presented as the mean \pm standard deviation, $\mathrm{n}=3$. ${ }^{\prime \prime} \mathrm{P}<0.05 \mathrm{vs}$. the control, ${ }^{\# \#} \mathrm{P}<0.01$ vs. the control; ${ }^{*} \mathrm{P}<0.05$ vs. H/R-treated cells, ${ }^{* *} \mathrm{P}<0.01$ vs. the H/R-treated cells. MRF, Myrica rubra flavonoids; H/R, hypoxia/reoxygenation; SOD, superoxide dismutase; CAT, catalase; GSH-Px, glutathione-peroxidase; MDA, malondiadehyde.

MRF inhibits H/R-induced apoptosis in H9c2 cells. The disruption of $\Delta \Psi \mathrm{m}$ is an early marker of apoptosis (22). Therefore, the possible effect of MRF on $\Delta \Psi \mathrm{m}$ was assessed by JC-1 staining, which exhibited a potential-dependent accumulation in the mitochondria (Fig. 6A). The anti-apoptotic effect of MRF was further corroborated through FITC-Annexin V/PI double staining (Fig. 6B). Cells incubated with MRF demonstrated its strong protective effect against the $\mathrm{H} / \mathrm{R}$-induced mitochondrial membrane potential depolarization (Fig. 6C). The apoptosis rate significantly increased in the $\mathrm{H} / \mathrm{R}$ group compared with the control group $(\mathrm{P}<0.01)$, while MRF treatment effectively alleviated the ratio of apoptotic cells compared with the $H / R$ group (Fig. 6D).
Caspase- 3 serves a key role in regulating the apoptotic cascade. As presented in Fig. 6E, the caspase-3 activity significantly increased in the $H / R$ group but relatively decreased in the $\mathrm{H} / \mathrm{R}$ combined with MRF group $(\mathrm{P}<0.05)$. Therefore, $\mathrm{MRF}$ exhibited an inhibitory effect on the caspase- 3 activity of H9c2 cells.

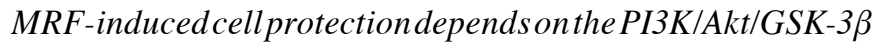
signal pathway. The PI3K/Akt/GSK-3 $\beta$ pathway serves an important protective role in myocardial $\mathrm{H} / \mathrm{R}$ injury (24). To investigate the potential signaling pathways contributing to the anti-apoptotic function of MRF, western blot analysis was used to investigate the effects of MRF on the expression 

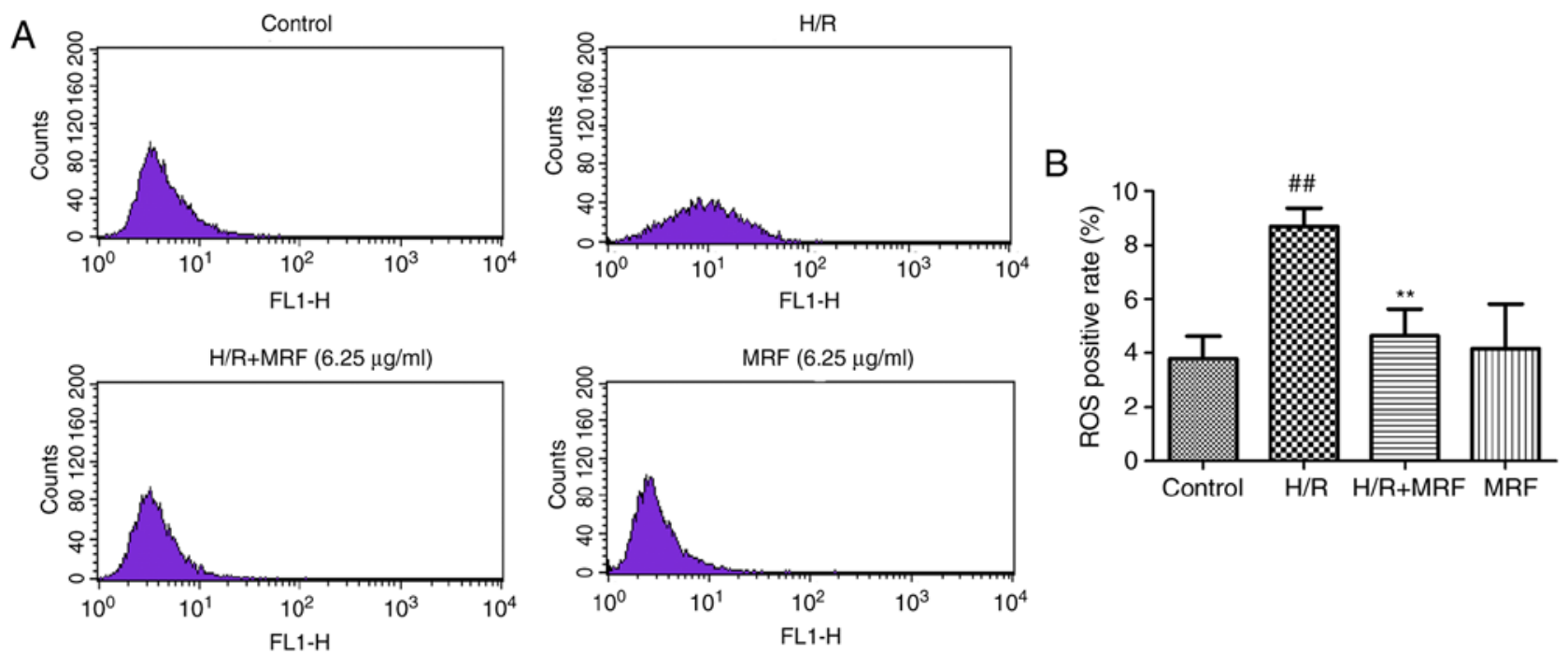

Figure 5. Effects of MRF on intracellular ROS levels in H9c2 cells. H9c2 cells were incubated with MRF (6.25 $\mu \mathrm{g} / \mathrm{ml})$ for $12 \mathrm{~h}$ following hypoxia for $6 \mathrm{~h}$ (A Flow cytometry analysis of intracellular ROS. (B) Statistical analysis of flow cytometry data. Data are expressed as the mean \pm standard deviation from three independent experiments. ${ }^{\# \#} \mathrm{P}<0.01$ vs. control; ${ }^{* *} \mathrm{P}<0.01$ vs. H/R-treated cells. MRF, Myrica rubra flavonoids; H/R, hypoxia/reoxygenation; ROS, reactive oxygen species.
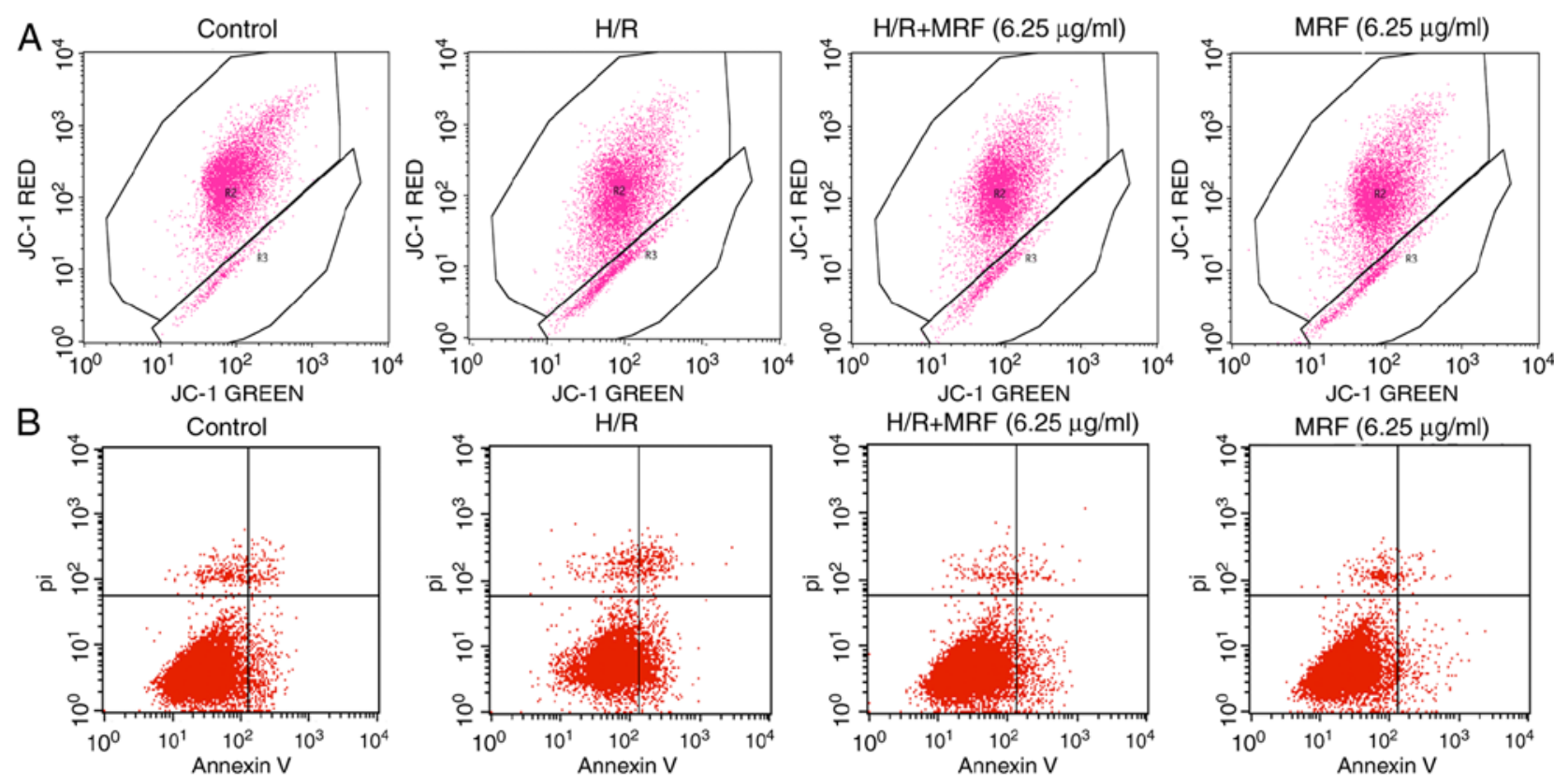

C

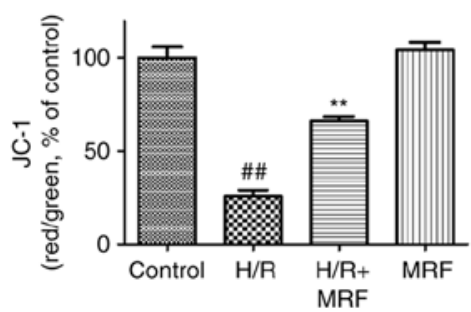

D

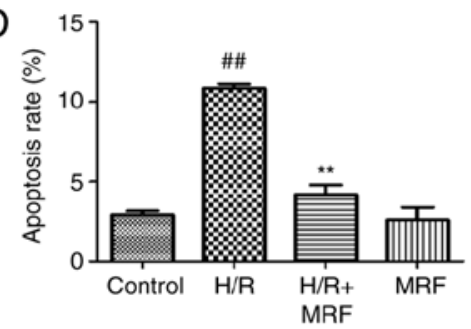

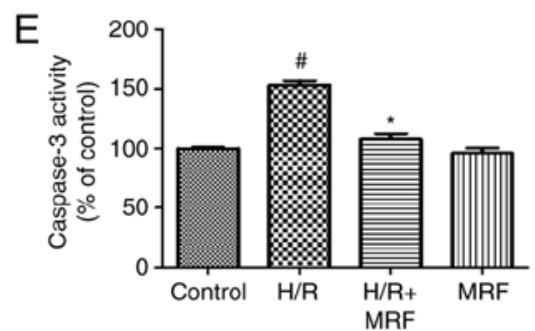

Figure 6. Effects of MRF on H/R-induced apoptosis. (A) Scatter diagram of JC-1 staining, as measured using flow cytometry. (B) Scatter diagram of Annexin V-PI double staining, as measured using flow cytometry. (C) The quantitative analysis of the ratio of red to green fluorescence intensity. (D) The quantitative analysis of apoptosis rate. (E) Caspase-3 activity was measured using a fluorometric assay. The data are presented as the mean \pm standard deviation from three independent experiments. ${ }^{\#} \mathrm{P}<0.05$ vs. the control, ${ }^{\# \#} \mathrm{P}<0.01$ vs. the control; ${ }^{*} \mathrm{P}<0.05 \mathrm{vs}$. H/R-treated cells, ${ }^{* *} \mathrm{P}<0.01 \mathrm{vs}$. H/R-treated cells. MRF, Myrica rubra flavonoids; H/R, hypoxia/reoxygenation; PI, propidium iodide.

of proteins associated with the PI3K/Akt/GSK-3 $\beta$ signaling pathways. The H/R group significantly decreased the levels of Akt and GSK-3ß phosphorylation compared with the control group $(\mathrm{P}<0.05 ;$ Fig. 7). In response to MRF treatment, 

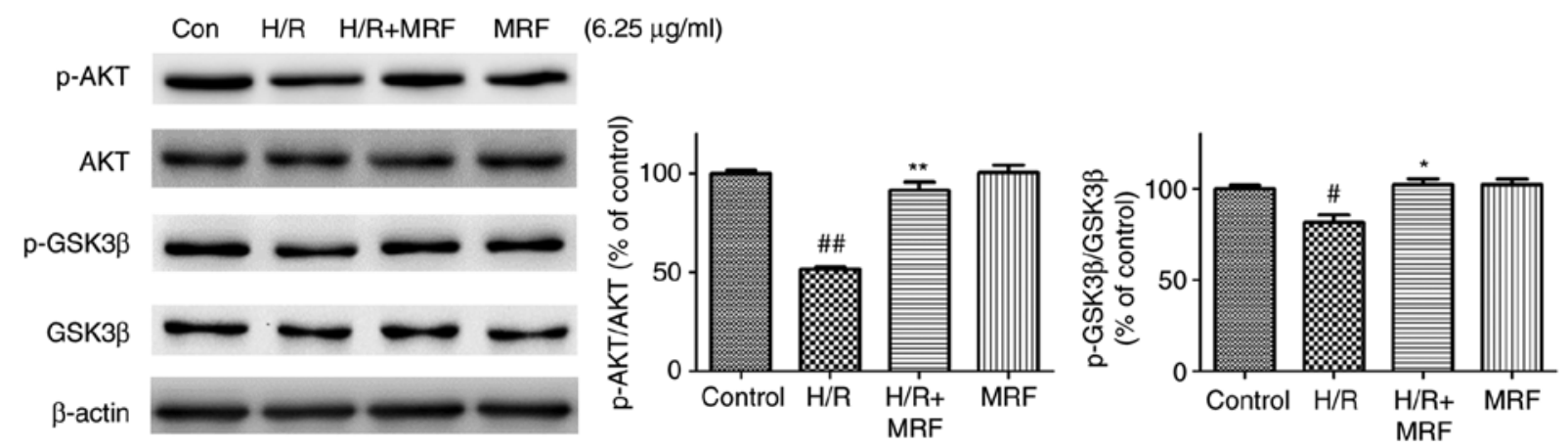

Figure 7. Effect of MRF on the expression levels of phosphoinositide 3 kinase/Akt/GSK-3 $\beta$ signaling pathway associated proteins in H/R-treated H9c2 cardiomyocytes. The cells were treated with MRF $(6.25 \mu \mathrm{g} / \mathrm{ml})$ for $12 \mathrm{~h}$ following hypoxia $(6 \mathrm{~h})$. Cell lysates were harvested and the expression ratio of p-Akt/Akt and p-GSK3 $\beta /$ GSK-3 $\beta$ were detected through western blot analysis. $\beta$-actin expression was examined as the protein loading control. The data are expressed as the mean \pm standard deviation from three independent experiments. ${ }^{~} \mathrm{P}<0.05$ vs. the control, ${ }^{\# \#} \mathrm{P}<0.01$ vs. the control; ${ }^{*} \mathrm{P}<0.05$ vs. the $\mathrm{H} / \mathrm{R}$-treated cells, ${ }^{* *} \mathrm{P}<0.01$ vs. the H/R-treated cells. MRF, Myrica rubra flavonoids; H/R, hypoxia/reoxygenation; Akt, protein kinase B; p-GSK-3 $\beta$, phosphorylated glycogen synthase kinase $3 \beta$.

the levels of phospho-Akt and phospho-GSK-3 $\beta$ were well preserved.

To further assess whether the PI3K/Akt/GSK-3 $\beta$ signaling pathway is essential for the antiapoptotic effect of MRF, the pharmacological inhibitor PI3K (LY294002) was adopted in the experiment. LY294002 reversed the cytoprotection of MRF against $\mathrm{H} / \mathrm{R}$ injury by decreasing the cell viability (Fig. 8A), increasing ROS levels (Fig. 8B), downregulating phosphorylation levels of the pro-survival proteins Akt and GSK-3 $\beta$, and antiapoptotic protein $\mathrm{Bcl}-2$ expression as well as upregulating the pro-apoptotic protein Bax expression (Fig. 8C and D). These results indicated that the activation of the PI3K/Akt/GSK-3 $\beta$ signaling pathway is involved in the protective effect of MRF against $\mathrm{H} / \mathrm{R}$ injury in cardiomyocytes.

\section{Discussion}

Natural flavonoids, which constitute a major part of effective components in traditional Chinese herbal medicines, are used as antioxidants for preventing and treating cardiovascular diseases for a number of years (25). For example, the leaf extracts of Ginkgo biloba that contain 24-27\% flavonoids as the major effective components have been widely known for their antioxidant capacities and are utilized to treat cardiovascular diseases worldwide (26). The bark of M. rubra is used as an astringent, antidote and antidiarrheal agent in oriental traditional medicine (12). A number of these flavonoid compounds possess outstanding antioxidant, anti-inflammatory and anti-hyperlipidemic effects, which are highly associated with the prevention of cardiovascular diseases $(14,15,27)$. Particularly, myricitrin and quercetin 3-rhamnoside, the major constituents of MRF, have been reported to prevent atherosclerosis and other associated cardiovascular diseases (28-31). In accordance with previous studies (25-31) supporting that flavonoids possess antioxidant actions and the present in vivo study, it was demonstrated that along with the increased SOD, GSH-Px and CAT activities and decreased MDA levels, MRF treatment fully prevented the overgeneration of ROS and neutralized the reduction in cell viability during $\mathrm{H} / \mathrm{R}$. These results directly revealed that the cardioprotective effects of MRF contributed to their role in reducing oxidative damage.
Oxidative stress is an essential mechanism causing cardiac myocyte apoptosis in pathological conditions, including I/R (32). ROS overproduction alters the mitochondrial structure and induces mitochondrial depolarization and the loss of $\Delta \Psi \mathrm{m}$ (33), leading to the release of proapoptotic molecules from the mitochondria and resulting in apoptosis (33). The results of the present study strongly demonstrated that MRF conditioning significantly improved the mitochondrial membrane potential, decreased the number of apoptotic cells and reduced caspase- 3 activation against H/R. Several studies have demonstrated that the $\mathrm{Bcl}-2 / \mathrm{Bax}$ ratio may decide the cellular threshold for apoptosis $(34,35)$. It was demonstrated that MRF enhanced the ratio of Bcl-2/Bax compared with the $\mathrm{H} / \mathrm{R}$ group. Given these results, it was hypothesized that MRF exerts cardioprotective effects by modulating intracellular ROS levels and regulating the apoptotic cascade.

Extensive studies have demonstrated that activating PI3K/Akt-dependent signaling prevents cardiac myocyte apoptosis and attenuates the myocardium from I/R injury $(19,29,36)$. GSK-3 $\beta$ is a critical, active enzyme that functions downstream of Akt (37). GSK-3 $\beta$ phosphorylation by Akt results in enzyme inactivation (37). GSK-3 $\beta$ inhibition protects against organ ischemic injury, oxidative stress and apoptosis (38). Therefore, it was hypothesized that the cardioprotective effect of MRF against H/R-induced apoptosis in H9c2 cardiomyocytes is associated with the PI3K/Akt/GSK3 $\beta$ signaling pathways. As expected, the results of the present study demonstrated that MRF treatment increased the levels of phosphorylated Akt and GSK3 $\beta$ compared with the H/R group. Notably, using the PI3K inhibitor LY294002 demonstrated that the pharmacological inhibition of PI3K blocked the MRF-induced cardioprotection against $H / R$ injury as demonstrated by the decreased cell viability, $\mathrm{Bcl}-2 / \mathrm{Bax}$ ratio and phosphorylation levels of GSK-3 $\beta$. Therefore, it was concluded that elevated myocardial PI3K/Akt signaling and the subsequent increased phosphorylation of GSK3- $\beta$ may serve important roles in the cardioprotective effects of MRF.

In conclusion, this study revealed that MRF protects H/R-induced apoptosis in H9c2 cardiomyocytes. The pharmacological actions of MRF promote cardioprotection by attenuating oxidative stress and inhibiting apoptosis. 
A

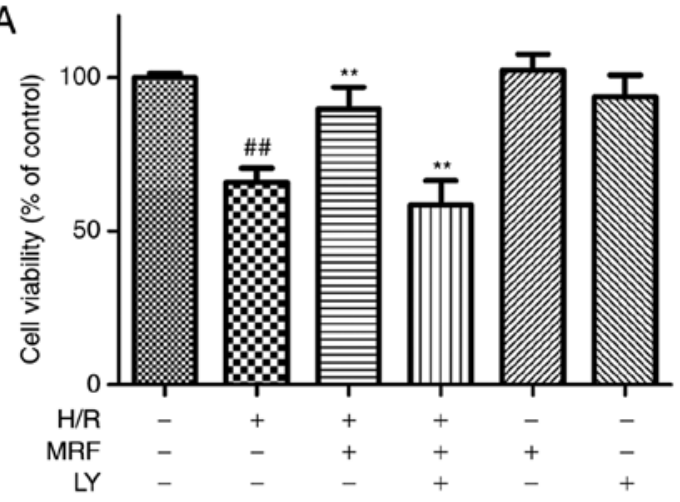

C

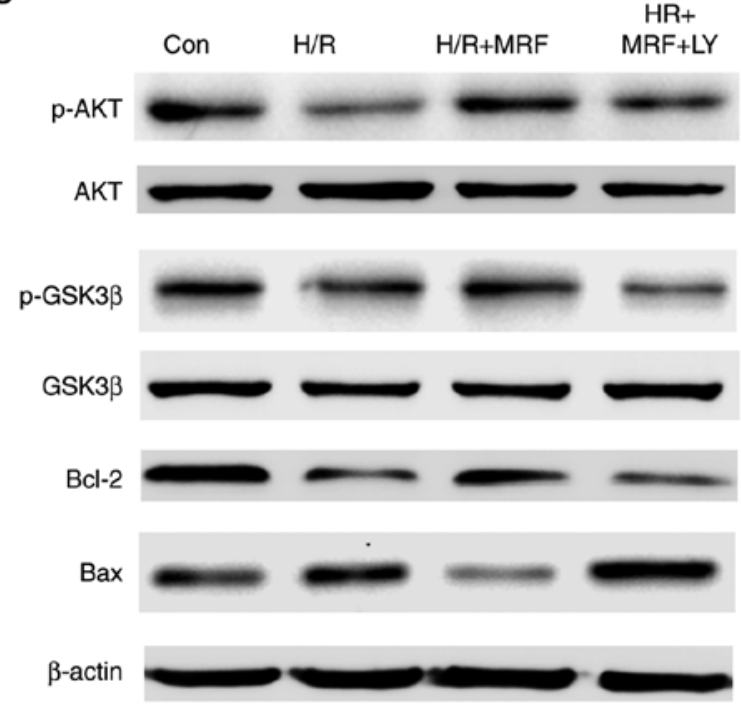

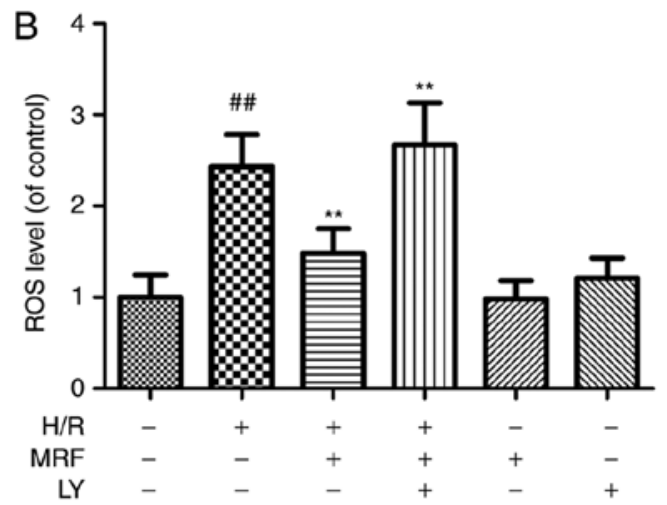
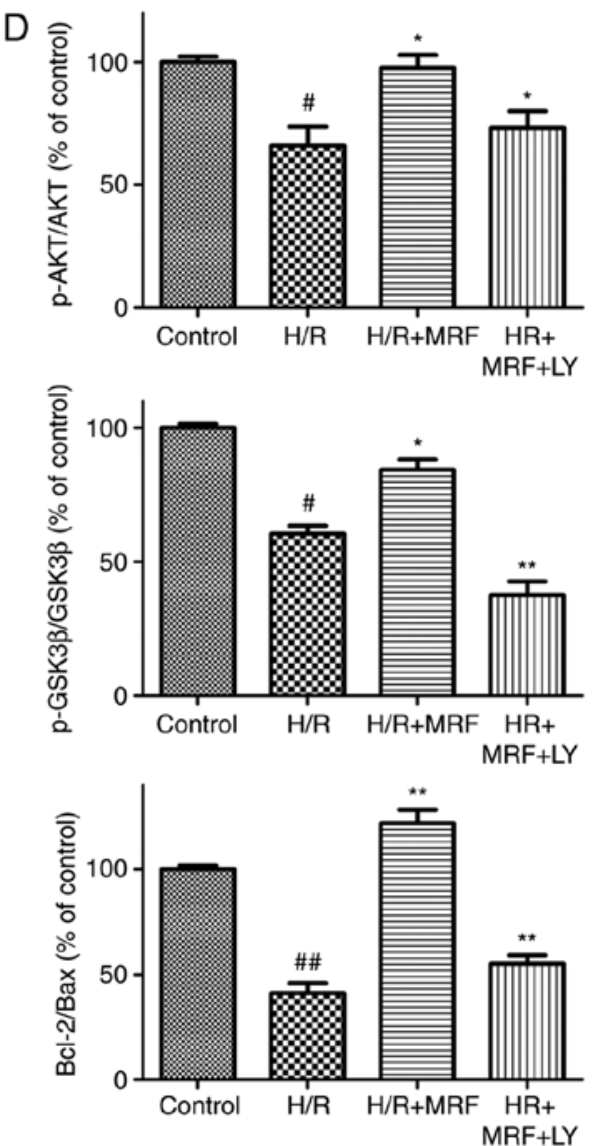

Figure 8. Effects of LY294002 (PI3K/Akt inhibitor) on the protection of MRF against H/R-stimulated cell death and apoptosis. (A) Effects of MRF and LY on cell viability in H/R-treated cardiomyocytes. (B) Effects of MRF and LY on ROS levels in H/R-treated cardiomyocytes. The intracellular ROS levels were

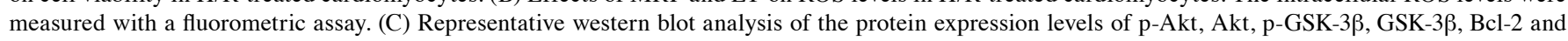
Bax in cardiomyocytes. (D) The ratios of p-Akt/Akt, p-GSK3 $\beta / G S K-3 \beta$ and Bcl-2/Bax were represented in bar graph. $\beta$-actin expression was examined as the protein loading control. The data are expressed as the mean \pm standard deviation from three independent experiments. ${ }^{~} \mathrm{P}<0.05$ vs. the control, ${ }^{\# \#} \mathrm{P}<0.01$ vs. the control; ${ }^{*} \mathrm{P}<0.05$ vs. the H/R-treated cells, ${ }^{* *} \mathrm{P}<0.01$ vs. the $\mathrm{H} / \mathrm{R}$-treated cells. ${ }^{*} \mathrm{P}<0.05$ vs. H/R+MRF-treated cells and ${ }^{* *} \mathrm{P}<0.01$ vs. the $\mathrm{H} / \mathrm{R}+\mathrm{MRF}$-treated cells. MRF, Myrica rubra flavonoids; H/R, hypoxia/reoxygenation; Akt, protein kinase B; p-GSK-3 $\beta$, phosphorylated glycogen synthase kinase 3 $\beta$; LY, LY294002; ROS, reactive oxygen species; PI3K, phosphoinositide 3 kinase.

Furthermore, the results of the present study indicate that the PI3K/Akt/GSK-3 $\beta$ pathway serves a critical role in the protective effects associated with MRF treatment. The present study provides rational evidence on MRF for further preclinical development of a formulation to improve cardiovascular disease. However, the overall mechanisms underlying the antiapoptotic effect of MRF require further investigations by TUNEL assay. In addition, further studies on the active flavonoids and their synergistically mechanisms of MRF against ischemic heart disease will be necessary.

\section{Acknowledgements}

Not applicable.

\section{Funding}

The present study was supported by the Major Scientific and Technological Special Project for 'Significant New Drugs Formulation' (grant nos. 2012ZX09103201-004 and 2012ZX09501001-004). 


\section{Availability of data and materials}

The datasets used and/or analyzed during the current study are available from the corresponding author on reasonable request.

\section{Authors' contributions}

GBS and XBS made substantial contributions to the design of the work and interpretation of data for the work. JXY, MW and RYW took part in the animal experiments in this study. MW, YL, RLP, RYW, SLD and WRD performed the experiments and collected the data. MW and YL analyzed the data and wrote the paper. All authors read and approved the manuscript.

\section{Ethics approval and consent to participate}

All procedures were approved by the Laboratory Animal Ethics Committee of the Institute of Medicinal Plant Development, Peking Union Medical College (Beijing, China) and complied with the Guide for the Care and Use of Laboratory Animals.

\section{Patient consent for publication}

Not applicable.

\section{Competing interests}

The authors declare that they have no competing interests.

\section{References}

1. Moran AE, Roth GA, Narula J and Mensah GA: 1990-2010 Global cardiovascular disease atlas. Glob Heart 9: 3-16, 2014.

2. Sharma V, Bell RM and Yellon DM: Targeting reperfusion injury in acute myocardial infarction: A review of reperfusion injury pharmacotherapy. Expert Opin Pharmacother 13: 1153-1175, 2012.

3. Kalogeris T, Baines CP, Krenz M and Korthuis RJ: Cell biology of ischemia/reperfusion injury. Int Rev Cell Mol Biol 298: 229-317, 2012.

4. Gerczuk PZ and Kloner RA: An update on cardioprotection: A review of the latest adjunctive therapies to limit myocardial infarction size in clinical trials. J Am Coll Cardiol 59: 969-978, 2012.

5. Marczin N, El-Habashi N, Hoare GS, Bundy RE and Yacoub M: Antioxidants in myocardial ischemia-reperfusion injury: Therapeutic potential and basic mechanisms. Arch Biochem Biophys 420: 222-236, 2003.

6. Fu Y, Qiao L, Cao Y, Zhou X, Liu Y and Ye X: Structural elucidation and antioxidant activities of proanthocyanidins from Chinese bayberry (Myrica rubra Sieb. et Zucc.) leaves. PLoS One 9: e96162, 2014.

7. Liu H, Qi X, Cao S and Li P: Protective effect of flavonoid extract from Chinese bayberry (Myrica rubra Sieb. et Zucc.) fruit on alcoholic liver oxidative injury in mice. J Nat Med 68: 521-529, 2014.

8. Feng C, Chen M, Xu CJ, Bai L, Yin XR, Li X, Allan AC, Ferguson IB and Chen KS: Transcriptomic analysis of Chinese bayberry (Myrica rubra) fruit development and ripening using RNA-Seq. BMC Genomics 13: 19, 2012.

9. Dai GH, Meng GM, Tong YL, Chen X, Ren ZM, Wang K and Yang F: Growth-inhibiting and apoptosis-inducing activities of Myricanol from the bark of Myrica rubra in human lung adenocarcinoma A549 cells. Phytomedicine 21: 1490-1496, 2014.

10. Sun C, Huang H, Xu C, Li X and Chen K: Biological activities of extracts from Chinese bayberry (Myrica rubra Sieb. et Zucc.): A review. Plant Foods Hum Nutr 68: 97-106, 2013.

11. Tao J, Morikawa T, Toguchida I, Ando S, Matsuda $\mathrm{H}$ and Yoshikawa M: Inhibitors of nitric oxide production from the bark of Myrica rubra: Structures of new biphenyl type diarylheptanoid glycosides and taraxerane type triterpene. Bioorg Med Chem 10: 4005-4012, 2002.
12. Matsuda H, Morikawa T, Tao J, Ueda K and Yoshikawa M: Bioactive constituents of Chinese natural medicines. VII. Inhibitors of degranulation in RBL-2H3 cells and absolute stereostructures of three new diarylheptanoid glycosides from the bark of Myrica rubra. Chem Pharm Bull (Tokyo) 50: 208-215, 2002.

13. Hobbs CA, Swartz C, Maronpot R, Davis J, Recio L, Koyanagi M and Hayashi SM: Genotoxicity evaluation of the flavonoid, myricitrin, and its aglycone, myricetin. Food Chem Toxicol 83: 283-292, 2015.

14. He K, Li X, Xiao Y, Yong Y, Zhang Z, Li S, Zhou T, Yang D, Gao $\mathrm{P}$ and Xin X: Hypolipidemic effects of Myrica rubra extracts and main compounds in C57BL/6j mice. Food Funct 7: 3505-3515, 2016

15. Zhang Y, Chen S, Wei C, Gong H, Li L and Ye X: Chemical and cellular assays combined with in vitro digestion to determine the antioxidant activity of flavonoids from Chinese Bayberry (Myrica rubra Sieb. et Zucc.) leaves. PLoS One 11: e0167484, 2016.

16. Lin W, Sun G, Pan R, Shen S and Wang T: Protective effects of myricetin against injury induced by $\mathrm{H}_{2} \mathrm{O}_{2}$ in vascular endothelial cells. Modern Chinese Med 17: 443-447, 2015.

17. Wang M, Meng XB, Yu YL, Sun GB, Xu XD, Zhang XP, Dong X, Ye JX, Xu HB, Sun YF and Sun XB: Elatoside C protects against hypoxia/reoxygenation-induced apoptosis in $\mathrm{H} 9 \mathrm{c} 2$ cardiomyocytes through the reduction of endoplasmic reticulum stress partially depending on STAT3 activation. Apoptosis 19: 1727-1735, 2014.

18. Sun J, Sun G, Meng X, Wang H, Wang M, Qin M, Ma B, Luo Y, $\mathrm{Yu} \mathrm{Y}$, Chen R, et al: Ginsenoside RK3 prevents hypoxia-reoxygenation induced apoptosis in H9c2 cardiomyocytes via AKT and MAPK pathway. Evid Based Complement Alternat Med 2013: 690190, 2013.

19. Wang M, Sun GB, Sun X, Wang HW, Meng XB, Qin M, Sun J, Luo Y and Sun XB: Cardioprotective effect of salvianolic acid B against arsenic trioxide-induced injury in cardiac H9c2 cells via the PI3K/Akt signal pathway. Toxicol Lett 216: 100-107, 2013.

20. Sun GB, Sun X, Wang M, Ye JX, Si JY, Xu HB, Meng XB, Qin M, Sun J, Wang HW and Sun XB: Oxidative stress suppression by luteolin-induced heme oxygenase-1 expression. Toxicol Appl Pharmacol 265: 229-240, 2012.

21. Li W, Wu Y, Liu X, Yan C, Liu D, Pan Y, Yang G, Yin F, Weng Z, Zhao D, et al: Antioxidant properties of cis-Z,Z'-3a.7a',7a.3a'dihydroxyligustilide on human umbilical vein endothelial cells in vitro. Molecules 18: 520-534, 2013.

22. Sun X, Sun GB, Wang M, Xiao J and Sun XB: Protective effects of cynaroside against $\mathrm{H}_{2} \mathrm{O}_{2}$-induced apoptosis in $\mathrm{H} 9 \mathrm{c} 2$ cardiomyoblasts. J Cell Biochem 112: 2019-2029, 2011.

23. Rodrigo R, Libuy M, Feliu F and Hasson D: Oxidative stress-related biomarkers in essential hypertension and ischemia-reperfusion myocardial damage. Dis Markers 35: 773-790, 2013

24. $\mathrm{Hu}$ Y, Li L, Yin W, Shen L, You B and Gao H: Protective effect of proanthocyanidins on anoxia-reoxygenation injury of myocardial cells mediated by the PI3K/Akt/GSK-3beta pathway and mitochondrial ATP-sensitive potassium channel. Mol Med Rep 10: 2051-2058, 2014.

25. Panche AN, Diwan AD and Chandra SR: Flavonoids: An overview. J Nutr Sci 5: e47, 2016.

26. Mahady GB: Ginkgo biloba for the prevention and treatment of cardiovascular disease: A review of the literature. J Cardiovasc Nurs 16: 21-32, 2002.

27. Kim HH, Kim DH, Kim MH, Oh MH, Kim SR, Park KJ and Lee MW: Flavonoid constituents in the leaves of Myrica rubra sieb. et zucc. with anti-inflammatory activity. Arch Pharm Res 36: 1533-1540, 2013.

28. Sun GB, Qin M, Ye JX, Pan RL, Meng XB, Wang M, Luo Y, Li ZY, Wang HW and Sun XB: Inhibitory effects of myricitrin on oxidative stress-induced endothelial damage and early atherosclerosis in ApoE-/- mice. Toxicol Appl Pharmacol 271: 114-126, 2013.

29. Qin M, Luo Y, Meng XB, Wang M, Wang HW, Song SY, Ye JX, Pan RL, Yao F, Wu P, et al: Myricitrin attenuates endothelial cell apoptosis to prevent atherosclerosis: An insight into PI3K/Akt activation and STAT3 signaling pathways. Vascul Pharmacol 70: 23-34, 2015.

30. Wang M, Sun GB, Du YY, Tian Y, Liao P, Liu XS, Ye JX and Sun XB: Myricitrin protects cardiomyocytes from hypoxia/reoxygenation injury: Involvement of heat shock protein 90. Front Pharmacol 8: 353, 2017. 
31. Choi JS, Bae JY, Kim DS, Li J, Kim JL, Lee YJ and Kang YH Dietary compound quercitrin dampens VEGF induction and PPARgamma activation in oxidized LDL-exposed murine macrophages: Association with scavenger receptor CD36. J Agric Food Chem 58: 1333-1341, 2010.

32. van Empel VP, Bertrand AT, Hofstra L, Crijns HJ, Doevendans PA and De Windt LJ: Myocyte apoptosis in heart failure. Cardiovasc Res 67: 21-29, 2005.

33. Sinha K, Das J, Pal PB and Sil PC: Oxidative stress: The mitochondria-dependent and mitochondria-independent pathways of apoptosis. Arch Toxicol 87: 1157-1180, 2013.

34. Kaushal GP, Liu L, Kaushal V, Hong X, Melnyk O, Seth R, Safirstein R and Shah SV: Regulation of caspase-3 and -9 activation in oxidant stress to RTE by forkhead transcription factors, Bcl-2 proteins, and MAP kinases. Am J Physiol Renal Physiol 287: F1258-F1268, 2004.

35. Lu D, Bai XC, Gui L, Su YC, Deng F, Liu B, Li XM, Zeng WS, Cheng BL and Luo SQ: Hydrogen peroxide in the Burkitt's lymphoma cell line Raji provides protection against arsenic trioxide-induced apoptosis via the phosphoinositide-3 kinase signalling pathway. Br J Haematol 125: 512-520, 2004.
36. Liu CW, Yang F, Cheng SZ, Liu Y, Wan LH and Cong HL: Rosuvastatin postconditioning protects isolated hearts against ischemia-reperfusion injury: The role of radical oxygen species, PI3K-Akt-GSK-3beta pathway, and mitochondrial permeability transition pore. Cardiovasc Ther 35: 3-9, 2017.

37. Martin M, Rehani K, Jope RS and Michalek SM: Toll-like receptor-mediated cytokine production is differentially regulated by glycogen synthase kinase 3. Nat Immunol 6: 777-784, 2005.

38. Liu T, Fang Y, Liu S, Yu X, Zhang H, Liang M and Ding X: Limb ischemic preconditioning protects against contrast-induced acute kidney injury in rats via phosphorylation of GSK-3beta. Free Radic Biol Med 81: 170-182, 2015.

This work is licensed under a Creative Commons Attribution-NonCommercial-NoDerivatives 4.0 International (CC BY-NC-ND 4.0) License. 